\title{
Prevalence Rate and Risk Factors of Depression in Outpatients with Premature Ejaculation
}

\author{
Xiansheng Zhang, Jingjing Gao, Jishuang Liu, Lei Xia, Jiajia Yang, Zongyao Hao, \\ Jun Zhou, and Chaozhao Liang \\ Department of Urology, The First Affiliated Hospital of Anhui Medical University, Hefei, Anhui 230032, China \\ Correspondence should be addressed to Chaozhao Liang; liang_chaozha0@163.com
}

Received 7 April 2013; Revised 9 June 2013; Accepted 9 June 2013

Academic Editor: Christian Schwentner

Copyright (c) 2013 Xiansheng Zhang et al. This is an open access article distributed under the Creative Commons Attribution License, which permits unrestricted use, distribution, and reproduction in any medium, provided the original work is properly cited.

\begin{abstract}
The purpose of this study is to investigate the prevalence rate and risk factors of depression in outpatients who were diagnosed with PE. Therefore, between September 2009 and September 2011, 1801 outpatients at andrology clinics were enrolled and consented to participate in our survey by completed a verbal questionnaire. It included the following: (1) demographic data (e.g., age, body mass index), (2) PE duration, medical history, and sexual history, (3) self-estimated intravaginal ejaculatory latency times, (4) the Zung Self-rating Depression Scale (SDS), and (5) the National Institute of Health Chronic Prostatitis Symptom Index (NIH-CPSI) and (6) the International Index of Erectile Function (IIEF-5). The results showed that a total of 1,206 patients were diagnosed with PE. The prevalence rate of depression in these PE patients was $26.78 \%$. Depression was associated with PE duration, NIH-CPSI score, and IIEF-5 score. Risk factors for depression specifically included PE durations for 13-24, 25-60, or $\geq 61$ months, CPSI scores of $15-30$ or $\geq 31$, and IIEF- 5 scores $<22$. These findings suggested that several associated factors (PE duration, CPSI scores, and IIEF-5 scores) were the risk factors of depression in men with PE.
\end{abstract}

\section{Introduction}

Premature ejaculation (PE) is a common male sexual dysfunction, which affects $20 \sim 30 \%$ of the male population [13]. Previous studies have shown that PE was associated with a range of negative psychological effects, including anxiety, depression, and distress in men and their female partners. Negative psychological effects might play an important role in precipitating or maintaining PE and seriously impair male health and couples' sexual relationships [4-6].

In a large observational study conducted by Patrick et al., men with PE reported a greater level of distress than men without PE (2.69 versus 0.69 ; 5 -point scale ranging from $0=$ not all distressed to $4=$ extremely distressed) [7]. Further analysis of the same survey showed that, relative to men without PE, men with PE had lower levels of sexual functioning and satisfaction as well as higher levels of personal distress and interpersonal difficulty [8]. Another survey of 334 Korean men revealed a significant relationship between PE and depression. Compared with control (no
PE) group, men with self-assessed PE suffered from various psychological problems, such as depression, low self-esteem, and sexual satisfaction [4].

Although putative negative psychological effects of PE have been discussed in recent years, correlations between PE and negative psychological effects have not been clarified, especially in China. In 2005, Lau et al. [9] investigated 298 young married Chinese men and confirmed that PE was significantly associated with mental health disturbances. However, that study did not include an in-depth examination of the factors relating the association. Therefore, in our survey, we determined the prevalence rate of and risk factors for depression in men who sought treatment for the complaint of ejaculating prematurely.

\section{Subjects and Methods}

2.1. Subjects. From September 2009 to September 2011, a noninterventional, observational, cross-sectional field survey 
TABLE 1: Diagnostic criteria for lifelong and acquired PE.

Lifelong PE

(1) Ejaculation occurs too early at nearly every intercourse

(2) Occurs with (nearly) every woman

(3) Occurs from about the first sexual encounter onwards

(4) Occurs in the majority of cases within $30 \mathrm{~s}$ (70\%), within $60 \mathrm{~s}$

(90\%), or between 1 and $2 \min (10 \%)$

(5) Remains rapid during life (70\%) or becomes aggravated with aging (30\%)

(6) The ability to delay ejaculation (i.e., withhold ejaculation at the moment of imminent ejaculation) may be diminished or lacking
Acquired PE

(1) Ejaculation occurs too early at some point in life

(2) Normal ejaculation experiences prior to the start of problems

(3) Occurs either suddenly or with a gradual onset

(4) Occurrence may be associated with the following

(i) Urological dysfunction (e.g., erectile dysfunction or prostatitis)

(ii) Thyroid dysfunction

(iii) Psychological or relationship problems

(5) The ability to delay ejaculation (i.e., withhold ejaculation at the moment of imminent ejaculation) may be diminished or lacking was conducted. Patients who sought treatment for the complaint of ejaculating prematurely were enrolled from andrology clinics located at three cities (namely, Hefei city, Suzhou city, and Wangjiang city) in Anhui province, China. This study were evaluated and approved by the Anhui Medical University Research Subject Review Board.

Subjects had to meet the following criteria to be included in this study: (1) age $\geq 18$ years; (2) heterosexual man in a stable, monogamous sexual relationship for at least 6 months; (3) able to speak Chinese. Each subject's medical history was carefully evaluated to rule out mental and/or other major medical diseases. Patients on medications that may affect ejaculatory function, such as antidepressants or phosphodiesterase type 5 inhibitors, were excluded.

2.2. Study Design and Procedure. Prior to study enrollment, all patients were informed about this survey. A careful medical and sexual history was also taken by an experienced clinician. Eligible patients were asked to provide written consent. Prior to survey administration, a presurvey was given to a small sample of subjects to modify the originally designed items to ensure that the questionnaire was comprehensive and easily understood.

This survey was conducted by face-to-face interviews. All subjects participated in the survey by completing a verbal questionnaire, which collected the following data: (1) age, body mass index (BMI), educational level, and occupation, (2) PE duration, medical and sexual history, (3) self-estimated intravaginal ejaculatory latency times (IELTs), (4) the Zung Self-rating Depression Scale (SDS), and (5) the National Institute of Health Chronic Prostatitis Symptom Index (NIHCPSI) and International Index of Erectile Function (IIEF5). The reliability of the instruments was assessed using Cronbach's alpha coefficient. The internal consistencies of the instruments (SDS, NIH-CPSI, and IIEF-5) were 0.80, 0.77, and 0.81 , respectively.

Based on ISSM criteria [10], a patient was diagnosed with $\mathrm{PE}$ if they experienced vaginal penetration for less than one minute, a loss of control, and/or negative sexual consequences. Following the classification of diagnosis, PE patients were then divided into two subgroups: (1) lifelong PE group, who suffered from PE since the first sexual experience and (2) acquired PE group, who experienced normal vaginal ejaculation, although early ejaculation had occurred at some point in their life [11]. Table 1 provides the diagnostic criteria for lifelong and acquired PE.

Depression was assessed by the SDS [12]. Both of these questionnaires consisted of 20 questions with a specific scoring system. The specific scoring system was applied in which each question had four possible answers, which were individually assigned $1,2,3$, or 4 points $(1=$ rarely, 2 = occasionally, 3 = frequently, and 4 = always). After the questionnaire was completed, the total score for the SDS was combined, divided by 80 , and then compared to a standard cutoff score for depression. A standard cut-off of 0.5 was employed such that a score $<0.5$ indicated no depression and a score $\geq 0.5$ confirmed depression.

The NIH-CPSI is a reliable, convenient, self-administered index that is widely used across scientific research and clinical studies. The assessment measures chronic prostatitis (CP) symptoms and their impact on daily life [13]. According to NIH-CPSI scores, CP symptoms can be separated into mild $(0-14)$, moderate $(15-30)$, or severe $(\geq 31)$ categories.

The IIEF-5 questionnaire contained five questions that were answered according to symptoms (scale range $0-5$ ). IIEF-5 scores $\geq 22$ points were rated as normal erectile function, while scores $<22$ points were rated as erectile dysfunction (ED).

2.3. Statistical Analysis. Collected data were analyzed by SPSS (SPSS Inc., v. 13.0, Chicago, IL, USA). The relationship between depression and associated factors in PE men was examined by the chi-square test. Multiple logistic regression was used to evaluate the risk factors of depression. Odds ratios (ORs) and 95\% confidence intervals (CIs) were calculated to examine association strength. Statistical significance was defined as $P<0.05$.

\section{Results}

Of 2,513 outpatients who met the inclusion criteria, 1,801 completed the questionnaire (425 rejected participation; 287 provided incomplete questionnaires), yielding a response rate of 71.67\%. Ultimately, 1206 (66.96\%, 1206/1801) patients were diagnosed with PE based on ISSM criteria. Among those 1206 men, 483 (40.05\%) patients had lifelong PE, and 723 (59.95\%) 
TABle 2: Demographic characteristics of men with PE.

\begin{tabular}{|c|c|c|c|c|c|c|}
\hline \multirow[t]{2}{*}{ Characteristics } & \multicolumn{2}{|c|}{$\begin{array}{c}\text { Subjects } \\
(N=1206)\end{array}$} & \multicolumn{2}{|c|}{$\begin{array}{l}\text { Lifelong PE } \\
(N=483)\end{array}$} & \multicolumn{2}{|c|}{$\begin{array}{c}\text { Acquired PE } \\
(N=723)\end{array}$} \\
\hline & $N$ & $\%$ & $N$ & $\%$ & $N$ & $\%$ \\
\hline \multicolumn{7}{|l|}{ Age, years } \\
\hline $20-29$ & 489 & 40.55 & 339 & 70.19 & 150 & 20.75 \\
\hline $30-39$ & 372 & 30.85 & 86 & 17.81 & 286 & 39.56 \\
\hline $40-49$ & 178 & 14.76 & 25 & 5.18 & 153 & 21.16 \\
\hline $50-66$ & 167 & 13.85 & 33 & 6.83 & 134 & 18.53 \\
\hline Mean \pm SD & \multicolumn{2}{|c|}{$35.23 \pm 11.45$} & \multicolumn{2}{|c|}{$28.86 \pm 6.23$} & \multicolumn{2}{|c|}{$39.48 \pm 12.15$} \\
\hline \multicolumn{7}{|l|}{ BMI, $\mathrm{kg} / \mathrm{m}^{2}$} \\
\hline$\leq 24$ & 475 & 39.39 & 203 & 42.03 & 272 & 37.62 \\
\hline$>24$ & 731 & 60.61 & 280 & 57.97 & 451 & 62.38 \\
\hline Mean \pm SD & \multicolumn{2}{|c|}{$26.12 \pm 3.18$} & \multicolumn{2}{|c|}{$24.17 \pm 3.12$} & \multicolumn{2}{|c|}{$27.42 \pm 4.14$} \\
\hline \multicolumn{7}{|l|}{ Duration, months } \\
\hline $0-12$ & 195 & 16.17 & 121 & 25.05 & 74 & 10.24 \\
\hline $13-24$ & 367 & 30.43 & 241 & 49.90 & 126 & 17.43 \\
\hline $25-60$ & 412 & 34.16 & 100 & 20.70 & 312 & 43.15 \\
\hline$\geq 61$ & 232 & 19.24 & 21 & 4.35 & 211 & 29.18 \\
\hline Mean \pm SD & \multicolumn{2}{|c|}{$32.15 \pm 20.52$} & \multicolumn{2}{|c|}{$27.22 \pm 13.47$} & \multicolumn{2}{|c|}{$37.45 \pm 19.23$} \\
\hline \multicolumn{7}{|l|}{ Educational status } \\
\hline Primary and illiterate & 51 & 4.23 & 31 & 6.42 & 20 & 2.77 \\
\hline Secondary school & 566 & 46.93 & 218 & 45.13 & 348 & 48.13 \\
\hline College & 519 & 43.03 & 180 & 37.27 & 339 & 46.89 \\
\hline Postgraduate and above & 70 & 5.80 & 54 & 11.18 & 16 & 2.21 \\
\hline \multicolumn{7}{|l|}{ Occupational status } \\
\hline Workers & 365 & 30.27 & 102 & 21.12 & 263 & 36.38 \\
\hline Students & 115 & 9.54 & 92 & 19.05 & 23 & 3.18 \\
\hline Drivers & 152 & 12.60 & 64 & 13.25 & 88 & 12.17 \\
\hline Farmers & 71 & 5.89 & 41 & 8.49 & 30 & 4.15 \\
\hline Officials & 132 & 10.95 & 83 & 17.18 & 49 & 6.78 \\
\hline Businessmen & 144 & 11.94 & 58 & 12.01 & 86 & 11.89 \\
\hline Other occupations & 227 & 18.82 & 43 & 8.90 & 184 & 25.45 \\
\hline
\end{tabular}

Subjects: men with PE; SD: standard deviation.

had acquired PE. The mean patient age, BMI, and PE duration were $35.23 \pm 11.45$ years, $26.12 \pm 3.18 \mathrm{~kg} / \mathrm{m}^{2}$, and $32.15 \pm 20.52$ months, respectively. Detailed demographic information of enrolled men with PE is summarized in Table 2.

According to the SDS, 323/1206 (26.78\%) patients experienced depression. Based on the diagnostic criteria of ED (IIEF-5 scores <22), 813/1206 (67.41\%) patients in the PE group were diagnosed with ED. Chi-square test results showed that depression in $\mathrm{PE}$ patients was significantly associated with PE duration $\left(X^{2}=17.425, P=0.001\right)$, NIHCPSI score $\left(X^{2}=44.500, P<0.001\right)$, and IIEF-5 score $\left(X^{2}=8.697, P=0.003\right)$. The following factors did not differ between depressed and not depressed men: age $\left(X^{2}=0.496\right.$, $P=0.920)$, BMI $\left(X^{2}=0.087, P=0.768\right)$, educational status $\left(X^{2}=0.749, P=0.862\right)$, occupational status $\left(X^{2}=2.022\right.$, $P=0.918)$, and $\mathrm{PE}$ subtype $\left(X^{2}=0.506, P=0.477\right)$
(Table 3). As reported in Table 4, multiple logistic regression showed that risk factors for depression among patients with PE included PE duration of 13-24 months (OR 1.42, CI 1.153.12), 25-60 months (OR 2.08, CI 1.33-4.97), or $\geq 61$ months (OR 4.02, 95\% CI 3.85-10.47), NIH-CPSI score of 15-30 (OR 2.01, 95\% CI 1.23-4.15) or $\geq 31$ (OR 4.98, 95\% CI 3.87-11.21), and IIEF-5 score <22 (OR 4.11, 95\% CI 3.43-9.15).

\section{Discussion}

Several studies have shown that men with PE may be influenced by negative psychological effects $[8,9,14]$. Negative psychological effects of PE can be displayed as personal distress, anxiety, and depression, which can impair physical and mental health of PE patients and their partners [15]. Indeed, a poor sexual relationship can produce feelings of frustration for both partners in a relationship $[16,17]$. 
TABLE 3: Factors associated with depression in men with PE.

\begin{tabular}{|c|c|c|c|c|c|c|}
\hline \multirow[t]{2}{*}{ Factors $(\mathrm{df})^{\mathrm{a}}$} & \multicolumn{2}{|c|}{$\begin{array}{l}\text { With depression } \\
\qquad(N=323)\end{array}$} & \multicolumn{2}{|c|}{$\begin{array}{l}\text { Without depression } \\
\qquad(N=883)\end{array}$} & \multirow{2}{*}{$\begin{array}{c}\text { Total } \\
(N=1206) \\
N\end{array}$} & \multirow[t]{2}{*}{$\begin{array}{l}{\left[\chi^{2}\right]} \\
P \text { value }\end{array}$} \\
\hline & $N$ & $\%$ & $N$ & $\%$ & & \\
\hline \multicolumn{7}{|l|}{ Age, years (3) } \\
\hline $20-29$ & 127 & 25.97 & 362 & 74.03 & 489 & \multirow{4}{*}{$\begin{array}{l}{[0.496]} \\
0.920\end{array}$} \\
\hline $30-39$ & 100 & 26.88 & 272 & 73.12 & 372 & \\
\hline $40-49$ & 48 & 26.97 & 130 & 73.03 & 178 & \\
\hline $50-66$ & 48 & 28.74 & 119 & 71.26 & 167 & \\
\hline \multicolumn{7}{|l|}{ BMI, kg/m² (1) } \\
\hline$\leq 24$ & 125 & 26.32 & 350 & 73.68 & 475 & \multirow{2}{*}{$\begin{array}{l}{[0.087]} \\
0.768\end{array}$} \\
\hline$>24$ & 198 & 27.09 & 533 & 72.91 & 731 & \\
\hline \multicolumn{7}{|l|}{ Educational status (3) } \\
\hline Primary and/or illiterate & 15 & 29.41 & 36 & 70.59 & 51 & \multirow{4}{*}{$\begin{array}{l}{[0.749]} \\
0.862\end{array}$} \\
\hline Secondary school & 147 & 25.97 & 419 & 74.03 & 566 & \\
\hline College & 140 & 26.97 & 379 & 73.03 & 519 & \\
\hline Postgraduate and above & 21 & 30.00 & 49 & 70.00 & 70 & \\
\hline \multicolumn{7}{|l|}{ Occupational status (6) } \\
\hline Workers & 103 & 28.22 & 262 & 71.78 & 365 & \multirow{7}{*}{$\begin{array}{l}{[2.022]} \\
0.918\end{array}$} \\
\hline Students & 28 & 24.35 & 87 & 75.65 & 115 & \\
\hline Drivers & 39 & 25.66 & 113 & 74.34 & 152 & \\
\hline Farmers & 16 & 22.54 & 55 & 77.46 & 71 & \\
\hline Officials & 39 & 29.55 & 93 & 70.45 & 132 & \\
\hline Businessmen & 38 & 26.39 & 106 & 73.61 & 144 & \\
\hline Other occupations & 60 & 26.43 & 167 & 73.57 & 227 & \\
\hline \multicolumn{7}{|l|}{ Subtype (1) } \\
\hline Lifelong PE & 124 & 25.67 & 359 & 74.33 & 483 & \multirow{2}{*}{$\begin{array}{l}{[0.506]} \\
0.477\end{array}$} \\
\hline Acquired PE & 199 & 27.52 & 524 & 72.48 & 723 & \\
\hline \multicolumn{7}{|l|}{ Duration, months (3) } \\
\hline $0-12$ & 39 & 20.00 & 156 & 80.00 & 195 & \multirow{4}{*}{$\begin{array}{l}{[17.425]} \\
0.001\end{array}$} \\
\hline $13-24$ & 83 & 22.62 & 284 & 77.38 & 367 & \\
\hline $25-60$ & 119 & 28.88 & 293 & 71.12 & 412 & \\
\hline$\geq 61$ & 82 & 35.34 & 150 & 64.66 & 232 & \\
\hline \multicolumn{7}{|l|}{ NIH-CPSI, scores (2) } \\
\hline $0-14$ & 145 & 20.80 & 552 & 79.20 & 697 & \multirow{3}{*}{$\begin{array}{l}{[44.500]} \\
<0.001\end{array}$} \\
\hline $15-30$ & 147 & 32.38 & 307 & 67.62 & 454 & \\
\hline$\geq 31$ & 31 & 56.36 & 24 & 43.64 & 55 & \\
\hline \multicolumn{7}{|l|}{ IIEF-5, scores (1) } \\
\hline$\geq 22$ & 84 & 21.37 & 309 & 78.63 & 393 & \multirow{2}{*}{$\begin{array}{l}{[8.697]} \\
0.003\end{array}$} \\
\hline$<22$ & 239 & 29.40 & 574 & 70.60 & 813 & \\
\hline
\end{tabular}

${ }^{\mathrm{a}}$ Degrees of freedom (df) for $\chi^{2}$ test, $N=1206$ in all cases.

In the current study, we found that $26.78 \%$ patients with PE suffered from depression. In addition, $25.67 \%$ of lifelong PE patients and $27.52 \%$ of acquired PE patients were diagnosed with depression. However, there was no significant correlation between PE subtype and depression. Moreover, the results of this study also showed that PE was not significantly associated with common demogrphaic factors, including age, BMI, educational status, and occupational status, suggesting that these factors likely do not influence the occurrence of depression in PE patients.

However, depression was significantly associated with PE duration. Specifically, multiple logistic regression indicated that PE durations extending beyond a year (13-24 months, $25-60$ months, or $\geq 61$ months) elevated risk of depression in PE patients. Considering the work of Graziottin and Althof [16], we thought that the relationship between PE duration 
TABLE 4: Risk factors revealed by multiple logistic regression for depression in men with PE.

\begin{tabular}{|c|c|c|c|c|}
\hline \multirow{2}{*}{ Risk factors } & \multirow{2}{*}{ Significance } & \multirow{2}{*}{ Odds ratio } & \multicolumn{2}{|c|}{ 95\% confidence interval } \\
\hline & & & Lower & Upper \\
\hline \multicolumn{5}{|c|}{ Duration, months } \\
\hline $0-12$ & 1.00 & & & \\
\hline $13-24$ & 0.01 & 1.42 & 1.15 & 3.12 \\
\hline $25-60$ & 0.00 & 2.08 & 1.33 & 4.97 \\
\hline$\geq 61$ & 0.00 & 4.02 & 3.85 & 10.47 \\
\hline \multicolumn{5}{|c|}{ NIH-CPSI, scores } \\
\hline $0-14$ & 1.00 & & & \\
\hline $15-30$ & 0.00 & 2.01 & 1.23 & 4.15 \\
\hline$\geq 31$ & 0.00 & 4.98 & 3.87 & 11.21 \\
\hline \multicolumn{5}{|l|}{ IIEF-5, scores } \\
\hline$\geq 22$ & 1.00 & & & \\
\hline$<22$ & 0.00 & 4.11 & 3.43 & 9.15 \\
\hline
\end{tabular}

and depression may best be explained as follows. Initially, the woman may keep silent to avoid hurting the man's feelings. Then, she and her partner may discuss reasons for losing sexual desire and/or failing to reach sexual climax. A continuous change in the woman's attitude across the duration of PE may increase the man's negative psychological effects, such as depression. Hence, in this way greater duration of PE may create or enhance emotional and physical dissatisfaction between partners.

It has been suggested that CP symptoms may be an important organic cause of PE [18-20]. Mehik et al. [21] showed that from $26.2 \%$ to $42.5 \%$ of men with CP (based on NIHCPSI score) or chronic pelvic pain syndrome experienced PE. In our survey, we discovered that the prevalence rate of depression was significantly associated with NIH-CPSI scores such that the higher the CPSI score, the more likely that the patient experienced depression. Further analyses revealed that NIH-CPSI scores above 15 were a distinct risk factor of depression in PE patients. Based upon these results, we speculated that prostatitis symptoms negatively affected a patients' mood, which might then induce a psychological burden and aggravate emotional and physical pain in $\mathrm{PE}$ patients.

A similar relationship was also identified between depression and ED, as demonstrated by IIEF-5 scores. Compared to patients with $\mathrm{PE}$ who have normal erectile function, men suffering from both PE and ED may be more vulnerable to be affected by depression. Indeed, IIEF- 5 scores less than 22 were the risk factors of depression in PE patients. Our findings support Buvat [22] who suggested that PE and ED may derive from a vicious cycle. As PE patients repeatedly attempt to reduce levels of excitation, in order to delay ejaculation, negative psychological effects may be induced. Consequently, the patient experiences loss of erectile function. Therefore, this vicious cycle will, in the long term, exacerbate negative psychological effects.

The current study has several limitations that require consideration. (1) Our survey sample included patients who presented complaints of PE and sought treatment. However, patients with PE complaints not referred to andrology clinics were not enrolled in our study. As a result, there may be some discrepancies between our findings and the true rate of depression among patients with PE. (2) We collected patient information by face-to-face interviews, which may have made some patients embarrassed due to the sensitive, personal nature of the research. While we believe that it is important to interact with patients, we certainly acknowledge that others methods (e.g., internet-based survey) can be used for data collection. (3) There is no control group of non-PE men in the study, making the comparisons with nonaffected populations difficult. Further research that includes comparative control groups should be conducted.

In conclusion, PE is a multifactored sexual dysfunction that is associated with negative psychological effects, which seriously impairs patient health and sexual relationships. In our survey, we found a substantial prevalence of depression among patients with PE (26.78\%). The prevalence was further elevated among patients with long-term PE, high NIH-CPSI score, and low IIEF-5 score. These variables were all risk factors for depression.

\section{Conflict of Interests}

All authors have no conflict of interests.

\section{Authors' Contribution}

Chaozhao Liang and Xiansheng Zhang participated in the design and conduct of the study. Xiansheng Zhang, Jingjing Gao, Jishuang Liu, Lei Xia, Jiajia Yang, Zongyao Hao, and Jun Zhou participated in data collection and analysis. Xiansheng Zhang, Jingjing Gao participated in writing the paper. All authors read and approved the final version of the paper. 


\section{Acknowledgment}

The authors thank Dr. Puyu Su for his expertise in statistical analysis.

\section{References}

[1] R. Rosen, H. Porst, and F. Montorsi, "The premature ejaculation prevalence and attitudes (PEPA) survey: a multi-national survey," in Proceedings of the 11th Word Congress of the International Society of Sexual and Impotence Research, 2004.

[2] D. Rowland, M. Perelman, S. Althof et al., "Self-reported premature ejaculation and aspects of sexual functioning and satisfaction," Journal of Sexual Medicine, vol. 1, no. 2, pp. 225$232,2004$.

[3] E. O. Laumann, A. Paik, and R. C. Rosen, "Sexual dysfunction in the United States: prevalence and predictors," Journal of the American Medical Association, vol. 281, no. 6, pp. 537-544, 1999.

[4] H. Son, S. H. Song, J. Y. Lee, and J. S. Paick, "Relationship between premature ejaculation and depression in Korean males," Journal of Sexual Medicine, vol. 8, no. 7, pp. 2062-2070, 2011.

[5] E. C. Serefoglu, O. Yaman, S. Cayan et al., "Prevalence of the complaint of ejaculating prematurely and the four premature ejaculation syndromes: results from the Turkish Society of Andrology Sexual Health Survey," Journal of Sexual Medicine, vol. 8, no. 2, pp. 540-548, 2011.

[6] M. McCabe, S. E. Althof, P. Assalian et al., "Psychological and interpersonal dimensions of sexual function and dysfunction," Journal of Sexual Medicine, vol. 7, no. 1, pp. 327-336, 2010.

[7] D. L. Patrick, S. E. Althof, J. L. Pryor et al., "Premature ejaculation: an observational study of men and their partners," Journal of Sexual Medicine, vol. 2, no. 3, pp. 358-367, 2005.

[8] D. L. Rowland, D. L. Patrick, M. Rothman, and D. D. Gagnon, "The psychological burden of premature ejaculation," Journal of Urology, vol. 177, no. 3, pp. 1065-1070, 2007.

[9] J. T. F. Lau, Q. Wang, Y. Cheng, and X. Yang, "Prevalence and risk factors of sexual dysfunction among younger married men in a rural area in China," Urology, vol. 66, no. 3, pp. 616-622, 2005.

[10] S. E. Althof, C. H. N. Abdo, J. Dean et al., "International society for sexual medicine's guidelines for the diagnosis and treatment of premature ejaculation," Journal of Sexual Medicine, vol. 7, no. 9, pp. 2947-2969, 2010.

[11] M. D. Waldinger and D. H. Schweitzer, "The use of old and recent DSM definitions of premature ejaculation in observational studies: a contribution to the present debate for a new classification of PE in the DSM-V,' Journal of Sexual Medicine, vol. 5, no. 5, pp. 1079-1087, 2008.

[12] W. W. Zung, "A self-rating depression scale," Archives of General Psychiatry, vol. 12, pp. 63-70, 1965.

[13] M. S. Litwin, M. McNaughton-Collins, F. J. Fowler Jr. et al., "The National Institutes of Health chronic prostatitis symptom index: development and validation of a new outcome measure," Journal of Urology, vol. 162, no. 2, pp. 369-375, 1999.

[14] K. F. Quek, A. A. Sallam, C. H. Ng, and C. B. Chua, "Prevalence of sexual problems and its association with social, psychological and physical factors among men in a Malaysian population: a cross-sectional study," Journal of Sexual Medicine, vol. 5, no. 1, pp. 70-76, 2008.
[15] U. Hartmann, M. Schedlowski, and T. H. C. Krüger, "Cognitive and partner-related factors in rapid ejaculation: differences between dysfunctional and functional men," World Journal of Urology, vol. 23, no. 2, pp. 93-101, 2005.

[16] A. Graziottin and S. Althof, "What does premature ejaculation mean to the man, the woman, and the couple?" Journal of Sexual Medicine, vol. 8, no. 4, pp. 304-309, 2011.

[17] P. Kempeneers, R. Andrianne, S. Bauwens, I. Georis, J. F. Pairoux, and S. Blairy, "Functional and psychological characteristics of belgian men with premature ejaculation and their partners," Archives of Sexual Behavior, vol. 42, no. 1, pp. 51-66, 2013.

[18] C. Z. Liang, X. J. Zhang, Z. Y. Hao, H. Q. Shi, and K. X. Wang, "Prevalence of sexual dysfunction in Chinese men with chronic prostatitis," BJU International, vol. 93, no. 4, pp. 568-570, 2004.

[19] C. Z. Liang, Z. Y. Hao, H. J. Li et al., "Prevalence of premature ejaculation and its correlation with chronic prostatitis in chinese men," Urology, vol. 76, no. 4, pp. 962-966, 2010.

[20] J. C. Nickel, J. Downey, D. Hunter, and J. Clark, "Prevalence of prostatitis-like symptoms in a population based study using the National Institutes of Health chronic prostatitis symptom index," Journal of Urology, vol. 165, no. 3, pp. 842-845, 2001.

[21] A. Mehik, P. Hellström, A. Sarpola, O. Lukkarinen, and M. R. Järvelin, "Fears, sexual disturbances and personality features in men with prostatitis: a population-based cross-sectional study in Finland," BJU International, vol. 88, no. 1, pp. 35-38, 2001.

[22] J. Buvat, "Pathophysiology of premature ejaculation," Journal of Sexual Medicine, vol. 8, no. 4, pp. 316-327, 2011. 


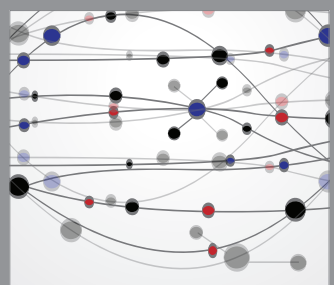

The Scientific World Journal
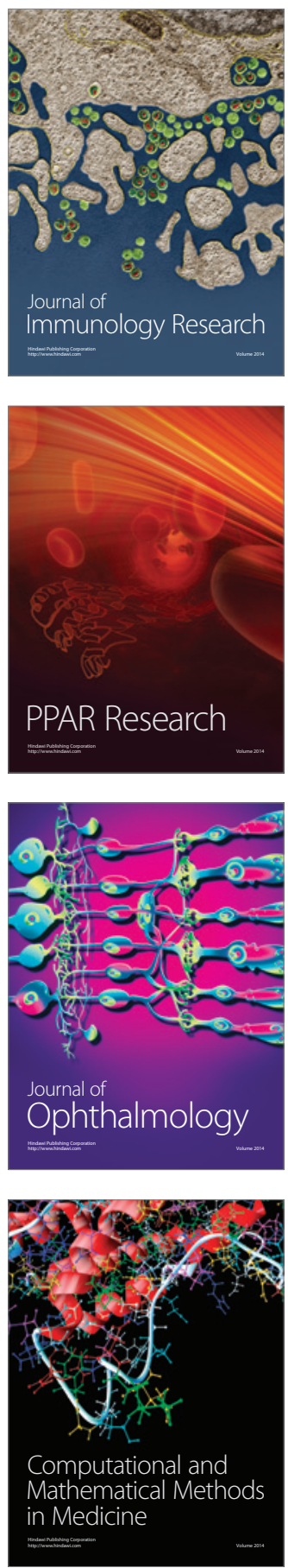

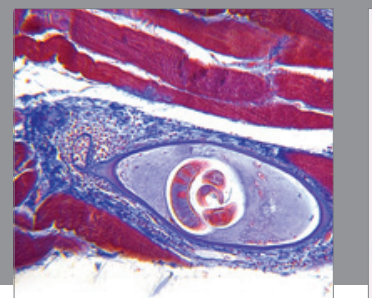

Gastroenterology

Research and Practice
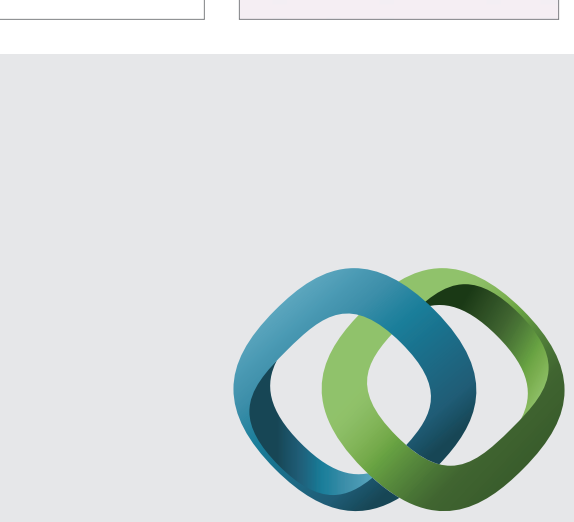

\section{Hindawi}

Submit your manuscripts at

http://www.hindawi.com
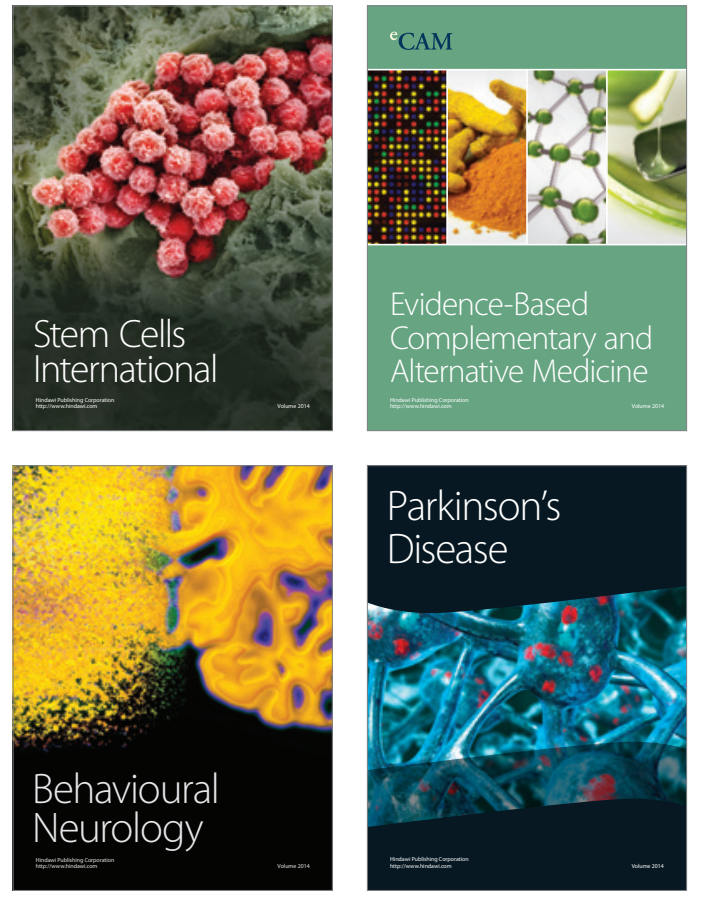
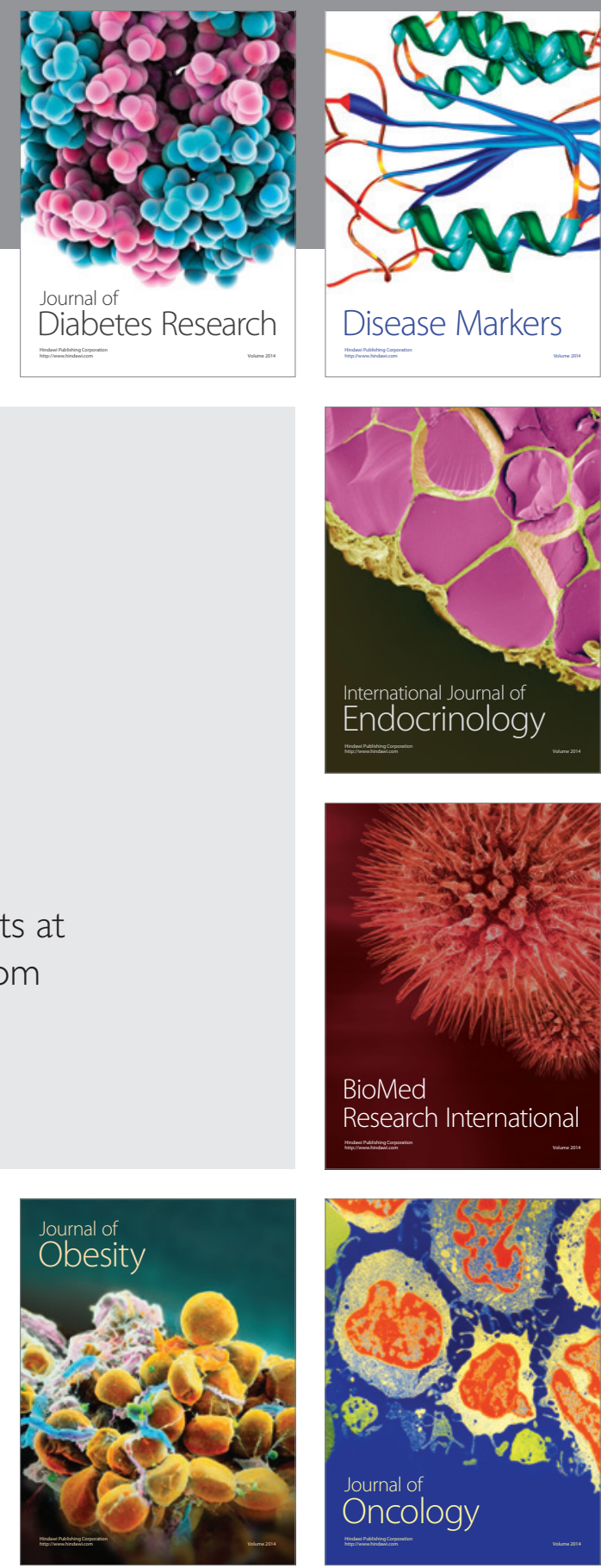

Disease Markers
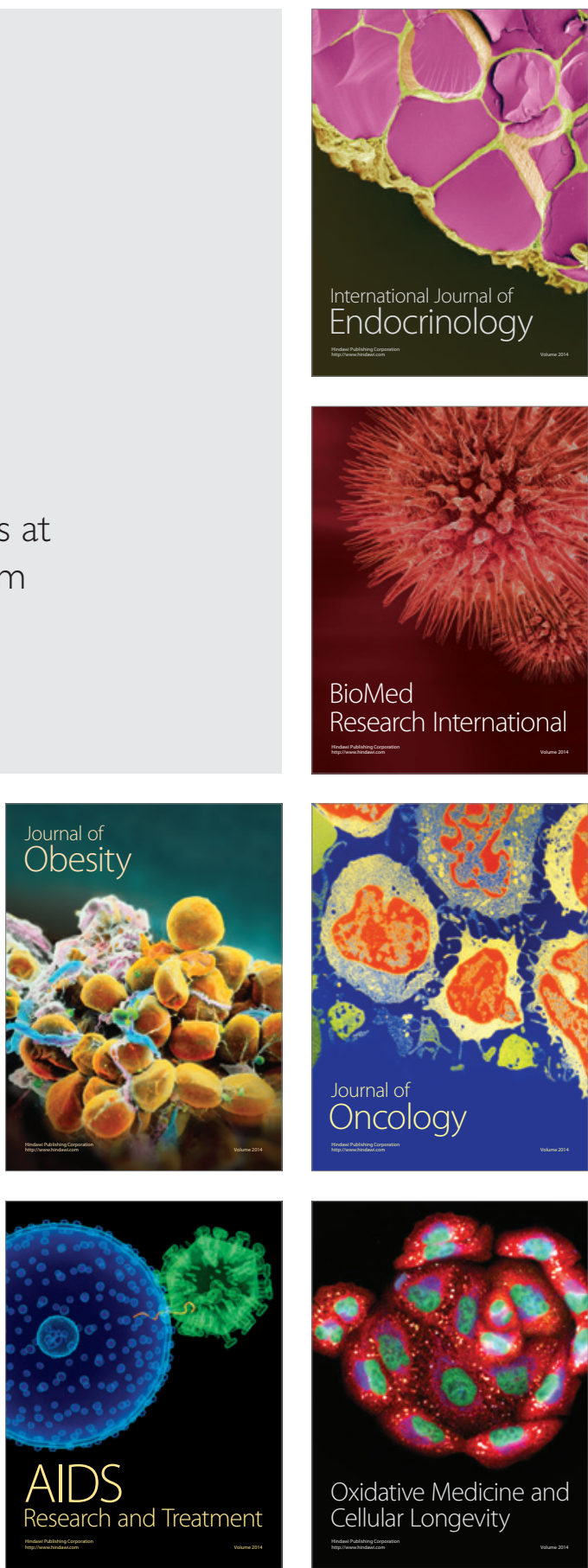